\title{
Association of matrix metalloprotease 1, 3, and 12 polymorphisms with rheumatic heart disease in a Chinese Han population

Wei Hu${ }^{1 \dagger}$, Yujia Ye ${ }^{1 \dagger}$, Yirui Yin², Peng Sang ${ }^{1}$, Linhua $\mathrm{Li}^{1}$, Jing Wang ${ }^{1}$, Wen Wan ${ }^{1}$, Rui Li ${ }^{1}$, Xiangfeng Bai ${ }^{3}$, Yuehui $X_{i} e^{4^{*}}$ and Zhaohui Meng ${ }^{1 *}$ (i)

\begin{abstract}
Background: Rheumatic heart disease (RHD) is an autoimmune disease triggered by acute rheumatic fever (ARF). Matrix metalloproteinases (MMPs) play an important role in the modulation of immune responses. The purpose of this study was to evaluate the association of MMP1, 3, and 12 promoter polymorphisms with RHD in a Han population in Southern China since the 3 genes are localized on the same chromosome and have a combined effect.

Methods: DNA samples were obtained from 90 adult patients with RHD and 90 control subjects. Polymorphisms in MMP1 (rs 1799750), MMP3 (rs3025058), and MMP12 (rs2276109) were genotyped by direct sequencing. Differences in genotype and allele frequencies of these polymorphisms were compared between the cases and the controls using Unconditional logistic regression models and Chi-squared test.

Results: The 2G/2G genotype of rs1799750 in MMP1 was associated with a significantly higher risk of RHD when compared with the $1 \mathrm{G} / 1 \mathrm{G}$ genotype $(\mathrm{OR}=3.227 ; 95 \% \mathrm{Cl}: 1.118-9.31 ; p=0.03)$. The frequency of allele $2 \mathrm{G}$ was higher in patients with RHD compared to the controls (69.4\% vs. $58.9 \%$; $p=0.048$ ) No significant differences in genotype and allele frequencies of rs3025058 in MMP3 and rs2276109 in MMP12 were found between the patients with RHD and the controls $(p>0.05)$.

Conclusions: Our results suggest that rs1799750 in MMP1 might be a risk factor for RHD in a Han population in Southern China, and individuals carrying the $2 \mathrm{G} / 2 \mathrm{G}$ genotype are likely more susceptible to RHD. In contrast, rs3025058 in MMP3 and rs2276109 in MMP12 might not contribute to the risk of developing RHD in this population. Further studies with larger samples and other ethnic populations are required to confirm these findings.
\end{abstract}

Keywords: Allele frequency, Extracellular matrix, Susceptibility

\section{Background}

As a consequence of untreated group A streptococcal pharyngitis, as many as $3-6 \%$ of individuals may develop acute rheumatic fever (ARF) [1], and $42-60 \%$ of those with ARF will eventually develop rheumatic heart disease (RHD) [2,3]. According to the Global Burden of Disease (GBD) Study, it is estimated that there were 34,232,795 cases of RHD and 345,000 deaths from RHD

\footnotetext{
* Correspondence: xieyuehuixyh@sina.com; mengzhgroup@aliyun.com ${ }^{\dagger}$ Equal contributors

${ }^{4}$ Department of Mathematics and Computer Science, Basic Medical College, Kunming Medical University, Kunming 650500, China

'Laboratory of Molecular Cardiology, Department of Cardiology, The First Affiliated Hospital of Kunming Medical University, Kunming 650032, China Full list of author information is available at the end of the article
}

globally in 2010 [4]. In China, the prevalence of RHD is around 1.86 cases per 1000 adults between 27 and 71 years of age [5]. Approximately $30-45 \%$ of children and young adults with ARF develop RHD due to permanent valvular damage [6]. The basic pathological change is degradation and remodeling of the extracellular matrix (ECM) [7], which is characterized by the destruction of glycosaminoglycans, proteoglycans collagen, and elastin $[8,9]$.

Matrix metalloproteinases (MMPs), which are members of the multidomain zinc endopeptidases family, are not only capable of degrading many ECM components associated with valvular remodeling and calcification [10], but they also can modulate immune responses by 
processing cytokines and chemokines to change their activity [11]. McQuibban GA et al. [12] demonstrated that the N-terminus of monocyte chemoattractant protein 1 (MCP1), MCP2 and MCP4 was cleaved by MMP1 and 3 to produce antagonist factors which dampen inflammatory processes. Further study has shown that MMP3 has a dual role in biphasic modulation of inflammatory mediator activity by cleaving Interleukin $1 \beta$ precursor into active form and degrading the biologically active cytokine [13]. RHD is an autoimmune disease that is triggered by ARF [14]. We can speculate that MMPs may be involved in the pathogenesis of RHD through an immune mechanism. However, there are few reports on the relationship between MMPs and RHD. In the present study, we will investigate the effect of $M M P s$ polymorphisms on RHD.

Genetic polymorphisms in the promoter region of $M M P s$ genes play an important role in the predisposition of patients to various diseases by altering transcriptional activity [15-18]. In the promoter of the MMP1 gene, an insertion (2G)/deletion (1G) polymorphism was detected at position - 1607 (rs1799750). It has been demonstrated that the $2 \mathrm{G}$ promoter processes higher transcriptional activity than the $1 \mathrm{G}$ promoter by binding more Ets-1 transcription factor [16]. This MMP1 promoter polymorphism has been reported to be associated with oligodendroglioma [19], coronary artery disease [20], osteoarthritis [21], and lumbar disc disease [22].

Another insertion (6A)/deletion (5A) polymorphism has been reported at position - 1612 (rs3025058) of the $M M P 3$ promoter. The $6 \mathrm{~A}$ promoter has a reduced transcription level due to its higher affinity to the repressor binding site [17]. This $M M P 3$ promoter polymorphism has been associated with osteoarthritis [23], lung cancer [24], and myocardial infarction [25].

A single nucleotide polymorphism (SNP) in the $M M P 12$ promoter region has been reported to influence transcriptional activity [18]. This A to $G$ substitution polymorphism is located at position - 82 (rs2276109) adjacent to the transcription factor activator protein-1 (AP-1). It has been suggested that this SNP may be a risk factor for rheumatoid arthritis [26], systemic sclerosis [27], ovarian carcinoma [28], and ischemic stroke [29].

Although MMPs polymorphisms have been associated with various diseases, the role of genetic polymorphisms in MMPs has not yet been evaluated in patients with RHD. In addition, MMP1, 3, and 12 are known to be adjacently localized on chromosome $11 \mathrm{q} 22.3$ [15] and these 3 loci are considered to act in cooperation with each other [30]. In the present study, we evaluated the associations of $3 M M P s$ polymorphisms, rs 1799750 in $M M P 1$, rs3025058 in $M M P 3$, and rs2276109 in MMP12, with RHD in a Han population in Southern China.

\section{Methods}

\section{Patients and control subjects}

We recruited 90 patients with RHD (46 males and 44 females) from the Department of Cardiovascular Surgery at the First Affiliated Hospital of Kunming Medical University. Diagnosis of RHD was based on modified Jones criteria as well as on transthoracic echocardiography (Phillips Agilent Sonos 5500, Amsterdam, Holland). Patients with one of the following cardiac manifestations were diagnosed with RHD: mitral stenosis including mitral valve area $\leq 2 \mathrm{~cm}^{2}$; the presence of leaflet thickening, commissural fusion, and alteration of the subvalvular apparatus; aortic regurgitation (with some degree of stenosis, aortic valve area $\leq 1.6 \mathrm{~cm}^{2}$ ); and tricuspid regurgitation. Carditis was found in $100 \%$ of the patients with RHD. No arthritis, subcutaneous nodules, chorea, or erythema marginatum was found in the patients. Patients with other heart complications and/or other inflammatory conditions were excluded from the study. We also recruited 90 age-, gender-, and ethnically-matched, unrelated healthy volunteers (41 males and 49 females) from the same hospital as the control subjects. This study was approved by the Institutional Research Ethics Committee of Kunming Medical University and followed the guidelines of the Declaration of Helsinki. All study participants were of self-reported Han ancestry and signed informed consent forms.

\section{Genotyping}

Genomic DNA was extracted from peripheral blood using E.Z.N.A. B Blood DNA Mini Kits following the manufacturer's instructions (Omega Bio-Tek, Inc., Norcross, GA, USA). Based on the sequences of $M M P 1$ (GenBank accession number: AY769434), MMP3 (GenBank accession number: AF405705), and MMP12 (GenBank accession number: AY856072) that were available from GenBank and using the Primer5 software (Premier Biosoft International, Inc., USA), the appropriate primers were designed and synthesized for MMP1 (rs1799750), MMP3 (rs3025058), and MMP12 (rs2276109) polymorphisms (TSINGKE Biological Technology, Beijing, China; Table 1). PCR amplifications were performed in a $30 \mu \mathrm{L}$ volume containing $30 \mathrm{ng}$ of genomic DNA, $2 \mu \mathrm{M}$ of forward primer, $2 \mu \mathrm{M}$ of reverse primer, $9 \mu \mathrm{L}$ of $\mathrm{ddH}_{2} \mathrm{O}, 0.2 \mathrm{mM} \mathrm{dNTP}$, and $15 \mu \mathrm{L}$ of $2 \times \mathrm{Ex} \mathrm{taq}^{\text {Tw }}$ Buffer and $1 \mathrm{U}^{\mathrm{Ex}} \operatorname{taq}^{\mathrm{Tm}}$ DNA polymerase (TSINGKE Biological Technology, Beijing, China). The cycling conditions used for PCR amplification were as follows: pre-denaturation at $95{ }^{\circ} \mathrm{C}$ for 5 min followed by 35 cycles of denaturation at $95{ }^{\circ} \mathrm{C}$ for $30 \mathrm{~s}$, annealing at $55^{\circ} \mathrm{C}$ for $30 \mathrm{~s}$, extension at $72{ }^{\circ} \mathrm{C}$ for $45 \mathrm{~s}$, and a final extension at $72{ }^{\circ} \mathrm{C}$ for $5 \mathrm{~min}$. The products were subjected to gel electrophoresis and visualized by Gelview (Bioteke, Beijing, China). The PCR products were sequenced using an ABI Prism 377 
Table 1 PCR and sequencing primers for the polymorphisms

\begin{tabular}{llll}
\hline Gene (polymorphism) & Forward primer & Reverse primer & $\begin{array}{l}\text { PCR product } \\
\text { size (bp) }\end{array}$ \\
\hline MMP1 (rs1799750) & 5' -AGTGGCAAGTGTTCTTTGGTCTC-3' & 5' -GTTCCACATTAAATTGTCTTGGGT-3' & 495 \\
MMP3 (rs3025058) & 5' -TTATCTATCAGGCTTTCCTCTAAAC-3' & 5' -CTGTGGCAATAAGATCCCTATGA-3' & 571 \\
MMP12 (rs2276109) & 5' -GGATAGGTGGACGTAGAGG-3' & 5' -CTTGCCAATTTCATAACAG-3' & 601 \\
\hline
\end{tabular}

automatic sequencer (PE Applied Biosystems, Foster City, CA, USA). Sequence data were analyzed using DNAMAN software (Lynnon LLC, San Ramon, CA, USA).

\section{Statistical analysis}

Statistical analysis was performed with SPSS version 17.0 (SPSS Inc., Chicago, IL, USA). Student's $t$ test was used to compare the mean age between the cases and the controls. A chi-squared test was used to compare the sex distribution between the cases and the controls and to test for the deviation of genotype distribution from the Hardy-Weinberg equilibrium. Unconditional logistic regression models were applied to compare the differences in the allele and genotype frequencies of the polymorphisms between the cases and the controls, adjusting for age, gender. $P<0.05$ was considered statistically significant.

\section{Results}

Demographic and clinical characteristics of patients with RHD and control subjects

The mean age of the patients with RHD and the controls were $51.0( \pm 5.4)$ and $50.9( \pm 4.9)$ years, respectively $(p=0.921)$. Of the RHD patients, $51.1 \%$ were male and $48.9 \%$ were female and in the control group, $45.6 \%$ were male and $54.4 \%$ were female $(p=0.55)$ (Table 2$)$.

Table 2 Demographic and clinical characteristics of patients with RHD and the controls

\begin{tabular}{llll}
\hline & $\begin{array}{l}\text { RHD patients } \\
(n=90)\end{array}$ & $\begin{array}{l}\text { Controls } \\
(n=90)\end{array}$ & p value \\
\hline $\begin{array}{lll}\text { Age (years) } \\
\text { Sex }\end{array}$ & $51.0 \pm 5.4$ & $50.9 \pm 4.9$ & 0.921 \\
Male & $46(51.1 \%)$ & $41(45.6 \%)$ & 0.55 \\
Female & $44(48.9 \%)$ & $49(54.4 \%)$ & \\
Clinical characteristics & & & \\
Carditis & $90(100 \%)$ & 0 & \\
Arthritis & 0 & 0 & \\
Subcutaneous nodules & 0 & 0 & \\
Chorea & 0 & 0 & \\
Erythema marginatum & 0 & & \\
\hline Age is represented as mean \pm SD & & & \\
\hline
\end{tabular}

Age is represented as mean $\pm S D$

$R H D$ rheumatic heart disease, $S D$ standard deviation
Genotype and allele distributions of MMP1, 3, and 12 polymorphisms in patients with RHD and control subjects The genotype distributions of the $M M P 1,3$, and 12 polymorphisms did not deviate from the Hardy-Weinberg equilibrium in both the cases and the controls $(p>0.05)$.

The overall genotype frequencies of rs1799750 in $M M P 1$ were not significantly different between the cases and the controls ( $p=0.072$; Table 3$)$. Compared to genotype $1 \mathrm{G} / 1 \mathrm{G}$, genotype $2 \mathrm{G} / 2 \mathrm{G}$ had a significantly higher frequency in the cases than in the controls $(45.6 \%$ vs. $34.4 \% ; p=0.03$; OR $=3.227,95 \% \mathrm{CI}: 1.118-9.31$ ), No significant difference in genotype $1 \mathrm{G} / 2 \mathrm{G}$ frequency was found between the cases and the controls (47.8\% vs. 48.9\%; $p=0.09$; Table 3). Compared to allele 1G, the frequency of allele $2 \mathrm{G}$ was significantly higher in the cases than in the controls $(69.4 \%$ vs. $58.9 \% ; p=0.048$; $\mathrm{OR}=0.644,95 \% \mathrm{CI}: 0.416-0.996)$.

No significant difference in the genotype and allele frequencies of rs3025058 in MMP3 was found between the cases and the controls ( $p=0.509$ and 0.473 , respectively; Table 3). Similarly, there was no significant difference in the genotype and allele frequencies of rs2276109 in MMP12 between the cases and the controls $(p=0.767$ and 0.576 , respectively; Table 3 ). Notably, no genotype G/G was observed for rs2276109 of MMP12 in both the cases and the controls.

\section{Discussion}

Twin studies have found that the risk of ARF in monozygotic twins with a history of ARF is increased by more than 6 times compared to that of dizygotic twins [31]. These findings provide evidence for the involvement of a host of genetic factors in susceptibility to RHD, which is the sequel to ARF in endemic conditions. Genetic association studies have shown that methylenetetrahydrofolate reductase (MTHFR) C677T polymorphism is associated with RHD [32] and other studies have suggested genetic associations between promoter polymorphisms in angiotensin-converting enzyme $(A C E)$ and interleukin $10(I L-10)$ and RHD [33, 34]. In the present study, we evaluated the associations of $3 \mathrm{MMPs}$ polymorphisms, MMP1 (rs1799750), MMP3 (rs3025058), and MMP12 (rs2276109), with RHD in a Han population in Southern China. Our study is the first to suggest an association between MMP1 (rs1799750) and RHD (Table 3). We showed that the MMP1-1607 2G/2G 
Table 3 Genotype and allele distributions of MMP1, 3, and 12 polymorphisms

\begin{tabular}{|c|c|c|c|c|}
\hline Gene (polymorphism) & $\begin{array}{l}\text { RHD } \\
\text { n (\%) }\end{array}$ & $\begin{array}{l}\text { Controls } \\
\mathrm{n}(\%)\end{array}$ & $p$ value & OR $(95 \% \mathrm{Cl})$ \\
\hline \multicolumn{5}{|l|}{ MMP1 (rs1799750) } \\
\hline Genotype & & & $0.072^{*}$ & \\
\hline $1 \mathrm{G} / 1 \mathrm{G}$ & $6(6.7)$ & $15(16.7)$ & - & (Ref.) \\
\hline $1 \mathrm{G} / 2 \mathrm{G}$ & $43(47.8)$ & $44(48.9)$ & 0.09 & $2.455(0.87-6.926)$ \\
\hline $2 G / 2 G$ & $41(45.6)$ & $31(34.4)$ & 0.03 & $3.227(1.118-9.31)$ \\
\hline \multicolumn{5}{|l|}{ Allele } \\
\hline $1 \mathrm{G}$ & $55(30.6)$ & $74(41.1)$ & - & (Ref.) \\
\hline $2 \mathrm{G}$ & $125(69.4)$ & $106(58.9)$ & 0.048 & $0.644(0.416-0.996)$ \\
\hline \multicolumn{5}{|l|}{ MMP3 (rs3025058) } \\
\hline Genotype & & & $0.509^{*}$ & \\
\hline $6 \mathrm{~A} / 6 \mathrm{~A}$ & $65(72.2)$ & $67(74.4)$ & - & (Ref.) \\
\hline $5 \mathrm{~A} / 6 \mathrm{~A}$ & $21(23.3)$ & $22(24.4)$ & 0.983 & $0.993(0.498-1.981)$ \\
\hline $5 \mathrm{~A} / 5 \mathrm{~A}$ & $4(4.4)$ & $1(1.1)$ & 0.230 & $3.908(0.421-36.242)$ \\
\hline \multicolumn{5}{|l|}{ Allele } \\
\hline $6 \mathrm{~A}$ & $151(83.9)$ & $156(86.7)$ & - & (Ref.) \\
\hline $5 \mathrm{~A}$ & $29(16.1)$ & $24(13.3)$ & 0.473 & $1.24(0.689-2.231)$ \\
\hline \multicolumn{5}{|l|}{ MMP12 (rs2276109) } \\
\hline Genotype & & & $0.767^{*}$ & \\
\hline $\mathrm{A} / \mathrm{A}$ & $85(94.4)$ & $83(92.2)$ & - & (Ref.) \\
\hline$A / G$ & $5(5.6)$ & $7(7.8)$ & 0.569 & $0.708(0.215-2.324)$ \\
\hline $\mathrm{G} / \mathrm{G}$ & $0(0.0)$ & $0(0.0)$ & - & - \\
\hline \multicolumn{5}{|l|}{ Allele } \\
\hline A & $175(97.2)$ & $173(96.1)$ & - & (Ref.) \\
\hline G & $5(2.8)$ & $7(3.9)$ & 0.576 & $0.717(0.223-2.307)$ \\
\hline
\end{tabular}

The genotype and allele with $p<0.05$ are shown in bold fonts

$O R$ odds ratio, $\mathrm{Cl}$ confidence interval, and Ref. reference

* $p$ value calculated from $2 \times 3$ contingency table

genotype was associated with a significantly higher risk of RHD when compared with the 1G/1G genotype $(\mathrm{OR}=3.227$; 95\% CI: 1.118-9.31; $p=0.03$; Table 3), and the frequency of the $2 \mathrm{G}$ allele was higher in RHD compared to the controls $(69.4 \%$ vs. $58.9 \% ; p=0.048$; Table 3). Studies have shown that MMP1 is expressed in all heart valves and that the mRNA transcript for MMP1 is significantly increased in patients with chronic valvular disease [35, 36]. Further studies have indicated that $M M P 1$ and its inhibitors play an important role in the development of an abnormal ECM characteristic of RHD and the MMP1/TIMP-1 ratio correlates positively with the rheumatic mitral valve area $[8,37]$.

MMP1 is located on chromosome $11 \mathrm{q} 22$ and produced by stromal fibroblast cells, macrophages, endothelial, and epithelial cells [38]. The level of MMP1 expression can be influenced by an insertion/deletion of guanine at position - 1607 in the promoter region; a core-binding site (5'-GGA-3') for the Ets family of transcription factors is created when 2 guanines are present instead of 1 guanine, leading to a higher expression of $M M P 1$ [16]. Our findings were in accordance with those of previous studies that suggested that patients who carry the $2 \mathrm{G}$ allele are predisposed to the development of several types of cancers, periodontitis, coronary artery disease, and peripheral arterial occlusive disease [39]. We hypothesized that the $2 \mathrm{G}$ allele in the MMP1 polymorphism might potentially increase the level of protein expression and accelerate the degradation of ECM, which provides the molecular basis for valvular tissue remodeling and repair during the development of RHD.

This MMP3 promoter polymorphism has been associated with osteoarthritis [22], lung cancer [24], and myocardial infarction [25]. The $M M P 3$ gene is located in the same chromosome region as MMP1. The MMP3-1612 polymorphism has been associated with serum $M M P 3$ titer in rheumatoid arthritis patients and congestive heart failure associated with RHD [40, 41]. Ye et al. first 
reported that the MMP3-1612 polymorphism was involved in the regulation of transcription by binding the transcriptional repressor protein $[17,42]$. These findings suggest that this functional polymorphism could be involved in the pathogenesis of RHD; however, we did not find a significant association between the MMP3-1612 polymorphism and RHD in this study, possibly due to the limited sample size. In addition, we observed in the present study that the 5A homozygote was very rare $(2.8 \%)$ in the Yunnan population (Southern China), which is consistent with the results from previous investigations in the Guangdong population (1.8\%, Southern China) and the Hebei population (2.5\%, Northern China) $[43,44]$. However, in other studies from British, Iranian, and Lithuanian populations, the frequency of the $5 \mathrm{~A}$ homozygote was $25.5,35.5$, and $26.2 \%$, respectively [45-47]. These findings suggest an ethnic difference in the $M M P 3$ gene polymorphism.

The MMP12 gene, MMP1, and MMP3 are located near each other on the same chromosome. In addition, the MMP12 expression has been reported to be upregulated in human heart valve disease [48]. Accordingly, we postulated that the MMP12 polymorphism might play an important role in the pathogenesis process of RHD; however, the present study did not show a significant association between the MMP12 polymorphism and RHD. The lack of a significant association of the MMP12 polymorphism with RHD could indicate that the MMP12 polymorphism might not be a major risk factor for RHD.

Although our study did not reveal correlation between MMP3-1612 6A/5A, MMP12 -82A/G polymorphisms and RHD in Han population, studies have shown a combined effect of MMP1-1607 1G/2G, MMP3-1612 6A/5A and MMP12-82A/G polymorphisms associated with esophageal adenocarcinoma (EA) risk in Caucasian [30]. The cause of the different conclusions may be difference in study population, low sample size or poor control-patient matching. In addition, the expression level of other $M M P S$ members were found elevated in patients with RHD, such as $M M P 2$ and $M M P 9$ [49, 50]. Elevated MMP2 levels in patients with RHD may be involved in atrial remodeling and atrial fibrosis by modulating the balance between $\mathrm{B}$-cell lymphoma 2 (Bcl-2) and $\mathrm{Bcl}-2$-associated $\mathrm{X}$ protein (BAX). Increased $M M P$ 9 may facilitate cardiac remodeling in RHD by playing a compensatory role for the decreased insulin-like growth factor (IGF)-I levels. Thus other MMPs members should be included in the polymorphism study due to their different pathogenic mechanisms in RHD.

There were several limitations in the present study. First, this case-control study had a relatively small sample size that might limit the statistical power to detect potential real genetic associations even though the controls were matched to the cases for age and sex. Further studies with larger samples are necessary to confirm our results. Second, our study subjects were confined to the Han population in Southern China. Additional studies in other ethnic populations are warranted to confirm our findings. Third, we only assessed the association between single polymorphisms of $M M P 1,3$, and 12 and RHD. Investigations into other polymorphisms in $M M P 1,3$, and 12 or other MMPs genes are required to elucidate the roles of MMPs genes in the development of RHD. Fourth, we did not use different methods to validate our results, such as RT-PCR, ELISA and/or immunohistochemical analysis.

\section{Conclusions}

In summary, we assessed the associations of $3 M M P s$ polymorphisms, MMP1 (rs1799750), MMP3 (rs3025058), and MMP12 (rs2276109), with RHD in a Han population in Southern China. Our study is the first to suggest an association between MMP1 (rs1799750) and RHD, but we did not find a significant association between $M M P 3$ (rs3025058) and MMP12 (rs2276109) and RHD. Further studies with different research methods, larger samples and other ethnic populations are required to confirm our results.

\section{Abbreviations}

ARF: Acute rheumatic fever; Cl: Confidence interval; ECM: Extracellular matrix; GBD: Global Burden of Disease; MMPs: Matrix metalloproteinases;

MTHFR: Methylenetetrahydrofolate reductase; OR: Odds ratio; RHD: Rheumatic heart disease; SD: Standard deviation; SNP: Single nucleotide polymorphism

\section{Acknowledgements}

We thank LetPub (http://www.letpub.com) for its linguistic assistance during the preparation of this manuscript.

\section{Funding}

This research was supported by grants from the National Natural Science Foundation of China (grant numbers 30860278, 81160025, and 81560075); the Leading Talent Program of Yunnan Province (L-201203); the Department of Science and Technology of Yunnan Province (2011Cl 057); the Joint Special Funds for the Department of Science and Technology of Yunnan Province-Kunming Medical University (2012FB005); and the Department of Education of Yunnan Province (ZD2010007).

\section{Availability of data and materials}

The datasets used and/or analysed during the current study available from the corresponding author on reasonable request.

\section{Authors' contributions}

$\mathrm{WH}$ and $Y$ Ye participated in the genetic analysis and drafted the manuscript. YYin and PS participated in the genetic analysis. LL and JW performed statistical analysis and sequence alignment. WW, RL, and XB collected the clinical data.

$Z M$ and $Y X$ conceived and coordinated the study, were involved in data analysis and revised the manuscript. All authors read and approved the final manuscript.

\section{Ethics approval and consent to participate}

This study was approved by the Institutional Research Ethics Committee of Kunming Medical University and followed the guidelines of the Declaration of Helsinki. All study participants were of self-reported Han ancestry and signed informed consent forms. 


\section{Competing interests}

The authors declare that they have no competing interests.

\section{Publisher's Note}

Springer Nature remains neutral with regard to jurisdictional claims in published maps and institutional affiliations.

\section{Author details}

'Laboratory of Molecular Cardiology, Department of Cardiology, The First Affiliated Hospital of Kunming Medical University, Kunming 650032, China. ${ }^{2}$ Yunnan Institute of Microbiology, Yunnan University, Kunming 650091, China. ${ }^{3}$ Department of Cardiovascular Surgery, The First Affiliated Hospital of Kunming Medical University, Kunming 650032, China. ${ }^{4}$ Department of Mathematics and Computer Science, Basic Medical College, Kunming Medical University, Kunming 650500, China.

\section{Received: 22 November 2016 Accepted: 30 January 2018}

\section{Published online: 20 February 2018}

\section{References}

1. Bryant PA, Robins-Browne R, Carapetis JR, Curtis N. Some of the people, some of the time: susceptibility to acute rheumatic fever. Circulation. 2009;119(5):742-53.

2. Ralph AP, Carapetis JR. Group a streptococcal diseases and their global burden. Curr Top Microbiol Immunol. 2013;368:1-27.

3. Beaudoin A, Edison L, Introcaso CE, Goh L, Marrone J, Mejia A, et al. Centers for Disease Control and Prevention (CDC): acute rheumatic fever and rheumatic heart disease among children-American Samoa, 2011-2012. MMWR Morb Mortal Wkly Rep. 2015;64(20):555-8.

4. Sims Sanyahumbi A, Colquhoun S, Wyber R, Carapetis JR. Global disease burden of group A streptococcus. In: Ferretti JJ, Stevens DL, Fischetti VA, editors. Streptococcus pyogenes: basic biology to clinical manifestations [Internet]. Oklahoma City: University of Oklahoma Health Sciences Center; 2016.

5. Zhimin W, Yubao Z, Lei S, Xianliang Z, Wei Z, Li S, et al. Prevalence of chronic rheumatic heart disease in Chinese adults. Int J Cardiol. 2006;107(3):356-9.

6. Carapetis JR, McDonald M, Wilson NJ. Acute rheumatic fever. Lancet. 2005; 366:155-68.

7. Grande-Allen K. Fibrotic vs. myxomatous remodeling of mitral valves. Conf Proc IEEE Eng Med Biol Soc. 2004;5:3737-40.

8. Banerjee T, Mukherjee S, Ghosh S, Biswas M, Dutta S, Pattari S, et al. Clinical significance of markers of collagen metabolism in rheumatic mitral valve disease. PLoS One. 2014;9(3):e90527.

9. Stephens EH, Nguyen TC, Blazejewski JG, Vekilov DP, Connell JP, Itoh A, et al. Extracellular matrix remodeling in wound healing of critical size defects in the mitral valve leaflet. Heart Vessel. 2016;31(7):1186-95.

10. Jung JJ, Razavian M, Challa AA, Nie L, Golestani R, Zhang J, et al. Multimodality and molecular imaging of matrix metalloproteinase activation in calcific aortic valve disease. J Nucl Med. 2015:56(6):933-8.

11. Parks WC, Wilson CL, López-Boado YS. Matrix metalloproteinases as modulators of inflammation and innate immunity. Nat Rev Immunol. 2004. 4(8):617-29.

12. McQuibban GA, Gong JH, Wong JP, Wallace $J \mathrm{~L}$, Clark-Lewis I, Overall CM. Matrix metalloproteinase processing of monocyte chemoattractant proteins generates CC chemokine receptor antagonists with anti-inflammatory properties in vivo. Blood. 2002;100(4):1160-7.

13. Schönbeck U, Mach F, Libby P. Generation of biologically active IL-1 beta by matrix metalloproteinases: a novel caspase-1-independent pathway of IL-1 beta processing. J Immunol. 1998;161(7):3340-6.

14. Perricone C, Rinkevich S, Blank M, Landa-Rouben N, Alessandri C, Conti F, et al. The autoimmune side of rheumatic fever. Isr Med Assoc J. 2014;16(10):654-5.

15. Ye S. Polymorphism in matrix metalloproteinase gene promoters: implication in regulation of gene expression and susceptibility of various diseases. Matrix Biol. 2000;19(7):623-9.

16. Rutter JL, Mitchell TI, Butticè G, Meyers J, Gusella JF, Ozelius L, et al. A single nucleotide polymorphism in the matrix metalloproteinasepromoter creates an Ets binding site and augments transcription. Cancer Res. 1998;58(23):5321-5.

17. Ye S, Eriksson P, Hamsten A, Kurkinen M, Humphries SE, Henney AM. Progression of coronary atherosclerosis is associated with a common genetic variant of the humanstromelysin-1 promoter which results in reduced gene expression. J Biol Chem. 1996;271(22):13055-60.
18. Jormsjö S, Ye S, Moritz J, Walter DH, Dimmeler S, Zeiher AM, et al. Allelespecific regulation of matrix metalloproteinase-12 gene activity is associated with coronary artery luminaldimensions in diabetic patients with manifest coronary artery disease. Circ Res. 2000;86(9):998-1003.

19. Kawal P, Chandra A, Rajkumar DTN, Ojha B. Correlations of polymorphisms in matrix metalloproteinase-1, -2 , and -7 promoters to susceptibility to malignant gliomas. Asian J Neurosurg. 2016;11(2):160-6.

20. Cui Q, Li Y, Duan C, Guo X, Liu X. Genetic polymorphism of matrix metalloproteinase- 1 and coronary artery disease susceptibility: a casecontrol study in a Han Chinese population. Genet Test Mol Biomarkers. 2014;18(12):826-31.

21. Lepetsos P, Pampanos A, Kanavakis E, Tzetis M, Korres D, Papavassiliou AG, et al. Association of MMP-1-1607 1G/2G (rs1799750) polymorphism with primary knee osteoarthritis in the Greek population. J Orthop Res. 2014; 32(9):1155-60.

22. Song YQ, Ho DW, Karppinen J, Kao PY, Fan BJ, Luk KD, et al. Association between promoter -1607 polymorphism of MMP1 and lumbar disc disease in Southern Chinese. BMC Med Genet. 2008;9:38.

23. Honsawek S, Malila S, Yuktanandana P, Tanavalee A, Deepaisarnsakul B, Parvizi J. Association of MMP-3 (-1612 5A/6A) polymorphism with knee osteoarthritis in Thai population. Rheumatol Int. 2013:33(2):435-9.

24. Fakhoury HM, Noureddine S, Tamim H, Chmaisse H, Makki R. Association of MMP3-117 (5A>6A) polymorphism with lung cancer in Lebanon. Genet Test Mol Biomarkers. 2012;16(8):988-90.

25. Wang J, Xu D, Wu X, Zhou C, Wang H, Guo Y, et al. Polymorphisms of matrix metalloproteinases in myocardial infarction: a meta-analysis. Heart. 2011;97(19):1542-6.

26. Ye S, Patodi N, Walker-Bone K, Reading I, Cooper C, Dennison E. Variation in the matrix metalloproteinase- $3,-7,-12$ and -13 genes is associated with functional status in rheumatoid arthritis. Int J Immunogenet. 2007; 34(2):81-5.

27. Manetti M, Ibba-Manneschi L, Fatini C, Guiducci S, Cuomo G, Bonino C, et al. Association of a functional polymorphism in the matrix metalloproteinase-12 promoter region with systemic sclerosis in an Italian population. J Rheumatol. 2010;37(9):1852-7.

28. Jia J, Kang S, Zhao J, Zhang X, Wang N, Zhou R, et al. Association of functional polymorphisms on MMP-12 and MMP-13 gene promoter region with epithelial ovarian carcinoma. Zhonghua Yi Xue Yi Chuan Xue Za Zhi. 2010;27(2):209-13.

29. Chehaibi K, Hrira MY, Nouira S, Maatouk F, Ben Hamda K, Slimane MN. Matrix metalloproteinase-1 and matrix metalloproteinase-12 gene polymorphisms and the risk of ischemic stroke in a Tunisian population. J Neurol Sci. 2014;342(1-2):107-13.

30. Bradbury PA, Zhai R, Hopkins J, Kulke MH, Heist RS, Singh S, et al. Matrix metalloproteinase 1, 3 and 12 polymorphisms and esophageal adenocarcinoma risk and prognosis. Carcinogenesis. 2009;30(5):793-8.

31. Engel ME, Stander R, Vogel J, Adeyemo AA, Mayosi BM. Genetic susceptibility to acute rheumatic fever: a systematic review and metaanalysis of twin studies. PLoS One. 2011;6(9):e25326.

32. Carlus SJ, Abdallah AM, Bhaskar LV, Morsy MM, Al-Harbi GS, Al-Mazroea AH, et al. The MTHFR C677T polymorphism is associated with mitral valve rheumatic heart disease. Eur Rev Med Pharmacol Sci. 2016;20(1):109-14.

33. Al-Harbi KM, Almuzaini IS, Morsy MM, Abdelaziz NA, Al-Balawi AM, Abdallah AM. Angiotensin-converting enzyme gene insertion/deletion polymorphism in Saudi patients with rheumatic heart disease. Saudi Med J. 2015;36(2):176-80.

34. Abdallah AM, Alnuzha A, Al-Mazroea AH, Eldardear AE, AlSamman AY, Almohammadi $Y$, et al. IL10 promoter polymorphisms are associated with rheumatic heart disease in Saudi Arabian patients. Pediatr Cardiol. 2016; 37(1):99-105.

35. Dreger SA, Taylor PM, Allen SP, Yacoub MH. Profile and localization of matrix metalloproteinase (MMPs) and their tissue inhibitors (TIMPs) in human heart valves. J Heart Valve Dis. 2002;11(6):875-80.

36. Aupperle H, Thielebein J, Kiefer B, März I, Dinges G, Schoon HA, et al. Expression of genes encoding matrix metalloproteinases (MMPs) and their tissue inhibitors (TIMPs) in normal and diseased canine mitral valves. J Comp Pathol. 2009;140(4):271-7.

37. Zhao $Y$, Zhou $X$, Liao $X$, Yang Z. Expression and significance of matrix metalloproteinase-1,9, tissue inhibitor of metalloproteinase-4 and extracellular matrix metalloproteinase inducer in the myocardium of congestive heart failure in patients withrheumatic heart diseases. Zhong Nan Da Xue Xue Bao Yi Xue Ban. 2009:34(8):790-5. 
38. Tetlow LC, Lees M, Woolley DE. Comparative studies of collagenase and stromelysin-1 expression by rheumatoid synoviocytes in vitro. Virchows Arch. 1995;425(6):569-76.

39. Arakaki PA, Marques MR, Santos MC. MMP-1 polymorphism and its relationship to pathological processes. J Biosci. 2009;34(2):313-20.

40. Tsukahara S, Shinozaki M, Ikari K, Mochizuki T, Inoue E, Tomatsu T, et al. Effect of matrix metalloproteinase-3 functional SNP on serum matrix metalloproteinase-3 level and outcomemeasures in Japanese RA patients. Rheumatology (Oxford). 2008;47(1):41-4.

41. Wang $X$, Yang L, Qi F, Zhu S, Wei L, Yang Y. Myocardial matrix metalloproteinase- 3 and matrix metalloproteinase inhibitor-1 expression in congestive heart failure. Zhonghua Nei Ke Za Zhi. 2002;41(7):453-5.

42. Ye S, Watts GF, Mandalia S, Humphries SE, Henney AM. Preliminary report: genetic variation in the human stromelysin promoter is associated with progression ofcoronary atherosclerosis. Br Heart J. 1995;73(3):209-15.

43. Shao Y, Deng M, Lian Z, Shi M, Jiang X. Matrix metalloproteinase-3 genotype distribution and its relation with blood pressure profiles in Guangzhourural population. Nan Fang Yi Ke Da Xue Xue Bao. 2013;33(4):586-9.

44. Fang $S$, Jin $X$, Wang $R$, Li Y, Guo W, Wang N, et al. Polymorphisms in the MMP1 and MMP3 promoter and non-small cell lung carcinoma in North China. Carcinogenesis. 2005;26(2):481-6.

45. Deguara J, Burnand KG, Berg J, Green P, Lewis CM, Chinien G, et al. An increased frequency of the $5 \mathrm{~A}$ allele in the promoter region of the MMP3 gene is associated with abdominalaortic aneurysms. Hum Mol Genet. 2007; 16(24):3002-7.

46. Motovali-Bashi M, Hojati Z, Hajihoseiny S, Hemmati S. The stromelysin-1 $5 \mathrm{~A} / 5 \mathrm{~A}$ genotype enhances colorectal cancer cell invasion in Iranian population. J Res Med Sci. 2012;17(10):962-6.

47. Liutkevičienè $\mathrm{R}$, Žaliaduonytè-Pekšienè $\mathrm{D}$, Žaliūnienè $\mathrm{D}$, Gustienè $\mathrm{O}$, Jašinskas $V$, Lesauskaite $V$, et al. Does matrix metalloproteinase-3 polymorphism play a role in age-related macular degeneration in patients with myocardial infarction? Medicina (Kaunas). 2012;48(8):404-9.

48. Bossé Y, Miqdad A, Fournier D, Pépin A, Pibarot P, Mathieu P. Refining molecular pathways leading to calcific aortic valve stenosis by studying gene expression profile of normal and calcified stenotic human aortic valves. Circ Cardiovasc Genet. 2009;2(5):489-98.

49. Diao SL, Xu HP, Zhang B, Ma BX, Liu XL. Associations of MMP-2, BAX, and BCl-2 mRNA and protein expressions with development of Atrial Fibrillation. Med Sci Monit. 2016;22:1497-507.

50. Lee SD, Chen LM, Kuo WW, Shu WT, Kuo WH, Huang EJ, Tsai CC, Li PC, Liu JY, Chen TH, Huang CY. Serum insulin-like growth factor-axis and matrix metalloproteinases in patients with rheumatic arthritis or rheumatic heart disease. Clin Chim Acta. 2006;367(1-2):62-8. Epub 2006 Jan 9.

\section{Submit your next manuscript to BioMed Central and we will help you at every step:}

- We accept pre-submission inquiries

- Our selector tool helps you to find the most relevant journal

- We provide round the clock customer support

- Convenient online submission

- Thorough peer review

- Inclusion in PubMed and all major indexing services

- Maximum visibility for your research

Submit your manuscript at www.biomedcentral.com/submit

) Biomed Central 